\title{
LXIV. On Aërial navigation
}

\section{Sir George Cayley Bart. F.R.S., \&c.}

To cite this article: Sir George Cayley Bart. F.R.S., \&c. (1816) LXIV. On Aërial navigation , Philosophical Magazine Series 1, 47:217, 321-329, DOI: 10.1080/14786441608628471

To link to this article: http://dx.doi.org/10.1080/14786441608628471

$$
\text { 曲 Published online: } 27 \text { Jul } 2009 .
$$

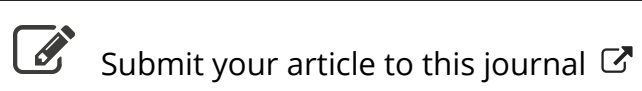

\footnotetext{
Џll Article views: 5
}

Q View related articles $\asymp$ 


\section{[ 321 ]}

LXIV. On Aërial Navigation. By Sir George Cayley, Bart. F.R.S., E゙c.

\section{To Mr. Tilloch.}

SIR, - I AM glad to see the subject of aërial navigation noticed by Mr. Lovel Edgeworth, and likewise by a gentleman under the signature of $\mathrm{T} . \mathrm{H}$. in your Magazine for March last. Mr. William Bland has likewise written an ingenious paper upon this subject in the Monthly Magazine for March. I wish to bring all those who interest themselves in this invention, to act in concert towards its completion, rather than to be jealons of each other respecting their own share of credit as inventors : incleed, unless we can realize our object, very little credit will be due to these speculations. Mr. Edgeworth, who upon good grounds puts in so early a claim to a knowledge of the principle of steering balloons by the inclined plane, has quite misconcived the nature of the principle upon which my former papers upon the subject of aërial navigation were founded, when he says that "Sir George Cayley has frequently proposed to impel flying bodies by letting them descend obliquely through the air, and forcing them in a contrary obliquity against the air by impelling them upwards." My plan rested upon the following fact : that if a plane of any given magnitude, say 100 square feet, were placed so as to make any small angle with an horizontal line, suppose an iuclination of one to ten; then, if it were propelled forward in the horizontal path, like a bird in the act of skimming, by a force of ten pounds, till the horizontal resistance of the air equalled this pressure, the plane would have power to sustain one hundred pounds weight during its progress. I proposed to create this slight horizoutal pressure by the power of a light first mover, several of which were there alluded to, particularly one where the combustion of oil of tar was made use of as the moving power. This engine had been exhibited in a working state to Mr. Rennie, Mr. Cartwright, and other gentlemen capable of appreciating its powers; and it appeared from the minutes of Mr. Chapman, civil engineer of Neweastle, that eighty drops raised eight hundred weight the height of twenty-two inches; hence a horse power may consume from ten to twelve pounds per hour. The expense of power, however, with this engine being much greater than with the steam-engine, the patentee never proceeded further than the original experiments. From this statement it is plain that the tacking operation alluded to by Mr. Edgeworth,-by "impelling them upuards," and then letting gravity operate in the descent,-was not any part of my plan, although, being acquainted with the principle of oblique Vol. 47. No. 217. May 1816. 
forces, and not having a proper first mover, I was obliged to try the experiments as to steadiness and steerage by merely allowing the vessel to sail from the top of a hill; and it was to this circumstance that I alluded in my observations upon Mr. Evans's paper, the descending half of the movement that gentleman proposed being perfectly similar to, and therefore corroborated by my experiments.

1 hare related this matter more minutely, because Mr. Edgeworth's statement rather gave me a claim to the principle of steering balloons by means of the inclined plane, which 1 do not possess. Indeed I hold it perfectly in nyy recollection, (although I cannot state either the name of the party or the publication in which I read the account, ) that an ingenious young man several years ago had tried some successful experiments on the steerage of balloons by the inclined plane, but had died before he completed his invention.

Should this subject gain importance by experimental success, this, and no doubt many other claims of various linds, will be attempted to be placed over the heads of those gentlemen, who now will, I hope, have the more substantial credit of realizing and perfecting the invention for the uses of mankind. For my own part, I shall sue for no share in the scramble respecting Montgolfier balloons, but that of braving the risible muscles of my friends in substituting acres for yards of cloth in their structure, unless indeed it be for the addition of a chimney, a most common, natural, and in this case particularly useful appendage to a fire. I shall however be extremely gratified in being able to claim the credit of standing on the same list with Mr. Edgeworth as a subseriber towards completing this noble art; -with this view I rexucst Mr. Tilloch to be kind enongh to permit a list of subscriptions to remain at his house till a few names be collected and a committec appointed ${ }^{-} ;-\ldots$ no one to be called upon for bis subscription money till such a sum be subscribed for as will be sufficient to try the first experiment proposed by the committee.

Iu my last paper it was stated that I had made some calculations relative to the quantity of fuel that would be consumed in propelling the Montgolfier balloon there described, at a relocity of twenty miles per hour, by the steam-engine. According to the returns made of the Cornwall engines, Mr. Woolf's engine raises about fifty millions of pounds, one foot high, with a bushel or eighty-four pounds of coal. Hence I estimate that twenty pounds of coal per mile would be consumed in this ope-

* I car have no ohjection to keep a list of the names of such gentlemen as may wish to contribute to an experinent of the hial reconmended. - A. T.

ration, 
ration, and therefore the expense would not be considerable.But as no more than 6500 pounds, the unconsuned power of this balloon, can be allowed for the weight of the engine, its water and fuel, besides that of an extensive surface for wafting, it appears upon estimating the weight of these things *, that this balloon, extensive as it is, is, as I before sairl, only the longboat of its species, and not quite large enough to take advantage of the saving power of the steam-engine at, so great a velocity as twenty miles per hour : though it will answer the purpose of a first experiment at fiften miles per hour with a proportionate saving of fuel.

Upon larger constructions, howescr, it will appear that aërial navigation will be performed much cheaper in a horizontal path by the stcam-engine, than upon the ascending and descending plan with the inclined plane. Several years ago I made many estimates of the application of first movers to these long balloons; but I always found that the enormous size required to be successfully driven by them, placed the proper scale of experiments quite out of the reach of any individual, and unfortunately of such magnitude as to render the public of that day, if appealed to, more incredulous than ever upon the subject. My own experiments were therefore confined to the inclined plane, which offers a good result upon a smaller construction. The introduction of the steam-hoat, together with " the steady march of the human nind" during so many years of unexampled scientific discovery, attended by practicable results in the rapid improvement of almost every art, will now enable me to state my ideas upon this subject, without stepping beyond the limits of many an incuiring mind. My former paper showed that the Montgolfier balloon there described was only the long-boat of this class of ressels; yet I felt obliged to pave the way for the introduction of so huge an infant obtruded upon the civilized worlt, by leading the unprepared mind from the contemplation of a hundred-gun ship of ninety yards in length, to a balloon of a humlred; and although in the course of this paper I shall be obliged to point out objects in reserve upon a larger scale, yet as a matter of experiment, I have nothing to add to the $b u l k$ of the balloon already described. It would be a great advantage to that vessel if the greater portion of its long chimney, from about twenty feet above the fire, were made of flexible materials well conted with the mixture of brick-dust, \&c. with which the firework-makers protect their materials:-this would allow of

* Coals for one hour - $\quad$ - 360 pounts

Water for do. - - $\quad 3540$

Weight of the wing or waftage 1000

Leaving anly - - $-\frac{1900}{6 \text { for }}$ for the weight of the engine. 
proper movement when the machine was at anchor to the eartli from some point under the prow. It ought likewise to be observed, that, owing to the internal pressure there will be exerted a power of about 460 pounds per lineal yard, endeavouring to tea: the cloth asunder. This power is easily provided against by it wide netting, although most cloths would sustain it without sich additional strength. Another circumstance to be adverted to, is the advantage that would arise from regulating the shape of the prow in the best manner for obviating the resistance of the air. Theory unfortunately is of little use upon this oceasion, for Nature, always true to itself, makes the prow of the lird concave, and that of the fish convex to their axes; whereas theory would appoint both alike. In the absence of all good theory, I shall, as proposed in one of my former papers, give the form of the woodcock from actual measurement, that bird having frequently to cross at least 500 miles of sea at one flight, ant Nature seeming to have united every contrivance to blend strength with lightriess in its structure; -hence it is more than probable, that as the resistance of the air was the obstacle which all this contrivance was calculated to overcome, the external form is nearly the best possible, being that which would more than all the rest tend to the ease of the performance.

Fig. 1, Plate IV. shows a section of this bird through its axis. Fig. 2 , is a tranverse section with the apparatus suspended. The ordinates are given in hundredth parts of an inch at the distance of one inch from each other. The weight of the individual bird corresponding with these measures was $12 \frac{1}{2}$ ounces, and the velocity of its leisure flight in calm air will have been about 28 miles per hour. It may possibly require a different form of prow for obviating resistance best at different velocities, and what may be the best form for a small object may not be so, even at the same velocity, for a large one; but notwithstanding this, I know no better guide, and shall therefore recommend the experiment to be made in the form of the prow delineated, as far as it can be made to agree with the flattened structure necessary in this instance for the trial of the inclined plane. That the practicability of constructing this balloon may be better judged of, I here subjoin the following estimates respecting it.

The quantity of cloth and the general appearance seem enormous; yet it must be recollected that it is only an infated bag, and that the 5750 square yards it consists of would all pack up in a cubical bore $3 \frac{1}{2}$ yards each way, allowing 1-5th of an inch for the thickness of each fold, which must be amply sufficient. The cloth 1 made use of in my experiments generally weighed half a pound per square yard; but probably, including the netting, the estimate for the present.purpose should be taken 


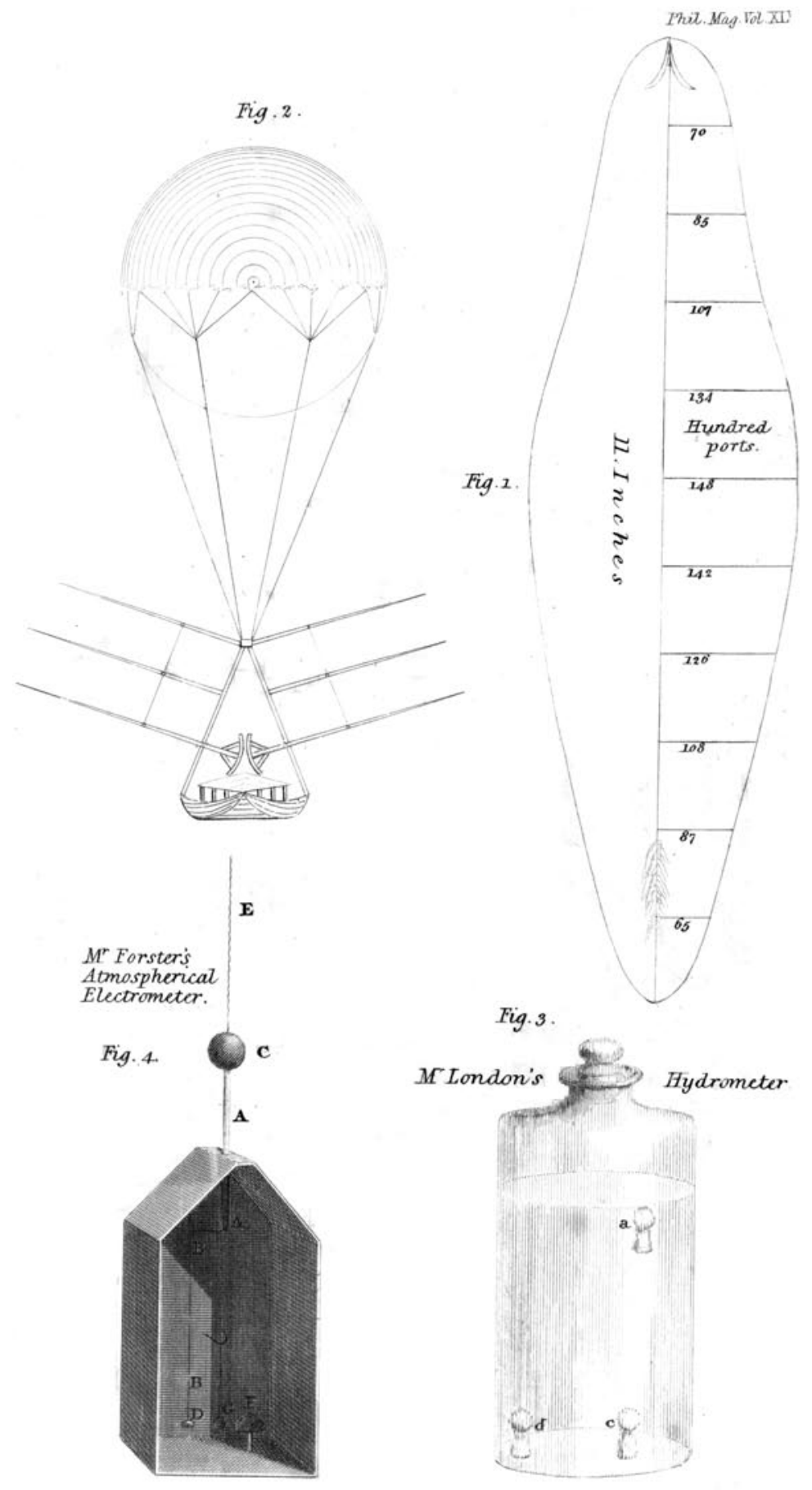


at a pound per yard; hence the weight would be 5750 pounds. Let the car, chimney, $8 \mathrm{c}$. be taken at 2000 , and there would be the power of 3050 left unoccupied, in addition to the power of 6,800 pounds for effecting its progressive motion : however, it would be necessary for one hour's travelling to carry about 2000 pounds weight of ficl, which would only leave power to convey a crew of seren men: hence it would be more suitable to carry about 20 men, and to reduce the ascending velocity to 15 miles per hour, allowing the descent to remain at the full speed, which would reduce the general speed to $17 \frac{1}{2}$ miles per hour.

This statement plainly shows that the Montgolfier balloon I have deseribed is the least that would be efficient, which 1 trust will shield me from the imputation of holding extravagant opiwions upon this subject in proposing it. Indeed the unwieldy bulk of these bodies is unwillingly thrust upon me by the result of calculations grounded upon the facts of the case.

'The danger attending the hydrogen gas balloon, where any first mover is used that acts by fre, is a great obstacle to their introduction; otherwise a balloon of this kind equal in power to the one described, would not exceed 70 yards in length, and would meet with rather less than half the resistance, and of course not consume more than half the power to drive it at the proposed velocity-there are other inconveniencies attending these balloons, and their eost in filling is not one of the least. The great resistance upon the prow must be balanced either by a firm wanded texture, or by internal condensation; the former is heavy and incapable of being folded up; and the latter wasteful, as it is impracticable to have it air-tight enough not to allow a vast escapage. This would oblige a double structure, one of thin oiled silk containing the gas, and one of a coarser texture surrounding it, which could receive the condensation necessary from commou air driven in occasionally by a pump; or perhaps, with some little contrivance an aperture at the point of the prow, receiving the full direct resistance of the external air, commensurate with the velocity of the balloon, would answer this purpose. The danger from fire might be greatly reduced by having the balloon at a considerable distance above the car, say 20 yards, and the surface for waftage might be so arranged as to permit of a safe descent even in the event of the balloon taking fire, and being obliged to be cut away.

It was my intention to have ascertained what proportion of azote with hydrogen gas would render it incombustible on its aceess to common air; but owing to an acciddent in the experiment immediately previous to my leaving home, this must be reserved to a future opportunity;-perhaps the adulteration required may be so great as to render the specific gravity of the 
mixture too nearly the same as atmospheric air to be of any use in this instance; but if azote in the ratio of one half, or even two to one, be ascertained to be sufficient, it will be an excellent step gained towards realizing this invention.

It is evident that if aërial navigation ever be brought home to the uses of man (and who, noting the progressive stages of society, can set a limit to the powers which the benevolent Author of his being designed him by proper gradations to become possessed of ;), it can only be done upon a scale of which the balloon described is the first unit; and although in the present day this unit is abundantly large enough in a practical point of view to occupy all the attention that can be afforded to the subject; yet 1 shall nevertheless obtrude a little in prospect upon the duties of our posterity respecting this art, as in a doing the capabilities that remain in store for our race will operate as an encouragement towards our availing ourselves of the first step. It has already been observed, that as balloons increase in size, the diminution of their relative resistance, when compared with their power, keeps pace with that increase. Upon this principle it is easy to show that a balloon of the form delineated, inflated with hydrogen gas, when extended to the length of 144 yards, will meet with no more resistance when compared with the weight it will sustain, including its materials, than the resistance of the bird compared with its weight. Surely we cannot wish for a better hasis for swift aërial navigation, than that of a vessel capable of suspending in the air as many multiples of the weight of the bird, as its resistance contains multiples of the resistance of the bird at the same velocity. This balloon would require 11880 square yards of cloth, which would fold within a cubic chest rather exceeding four yards each way, if of single structure; but I have taken it as a clouble structure, which would of course require two such spaces, and the weight at two pounds per yard will be 24000 pounds. I allow 17000 pounds for the other materials, including a surface of the necessary extent for waftage; when, deducting these weights, the supporting power, which is 163,000 pounds, will be reduced to 122,000 pounds, or 50 tons. This power remains to be divided in a proper ratio between the wcight of the first mover and that of the cargo or crew intended to be conveyed. Although two-thirds of the weight of most birds is devoted to the muscles of its wings, and arguing from the rapid consumption of their food, that their muscles may be more energetic than thase of quadrupeds, weight for weight; yet it is improbable that this excess is in any great proportion. The famous race-horse Eclipse is snid to have gone for one mile at the rate of 60 miles per hour, which is a far greater velocity than any bird whose flight I have meastred; and 
he had the disadvantage of carrying the weight of a man upon his back. If therefore the energies of birds be taken at double those of quadrupeds in this statement, more than an ample allowance is made in their favour. This power in birds is chiefiy employed in the waftage necessary for their support, and a smaller portion of it is applied to overcome the direct resistance of their body: but in the case of the balloon the supporting power is already obtained, and the whole energies of the first mover will be directed towards overcoming the resistance of the prow only, which is in no greater proportion to the weight of the whole apparatus than that of the bird to its weight.

Upon estimating the probable weight even of steam-engines upon a large scale, it appears that 160 pounds per horse power is an ample allowance with its load of coal and water for one hour *; and as the water is a considerable part of the whole, and can be recovered again for the use of the ergine by permiting the steam to pass within the double coats of the balloon, and to be thus exposed to so extensive a cooling surface, it is probable that 200 pounds per horse power will be more than sufficient for working twelve hours without any further supply of water or 'fucl-with a velocity of 20 miles per hour in calm air, this length of time would imply a stage of 240 miles. The steamhorse power raising 550 pounds one foot high per second, is considered by engineers as exceeding the average power of the largest dray-horses one-fourth. Upon weighing one of these animals of ahout the middle size, I found it to be fourteen himdred weight or 1568 pounds; and I am informed some of the largest of these horses have weighed a ton.-But if we take the smaller weight as approaching the average, we must increase it onefourth part to make an animal equal in power to the steamhorse: hence the weight of the steam-horse will be as 200 pounds to 1950 pounds when compared to that of the living animal. And to follow the argument I have been using, if the

* Estimate of the Weight of an Expansize Steam-enginc of 100 Hlorses Puzier.

Weight of a cylinder $2 \mathrm{ft}$. 4 inch. diameter by $4 \mathrm{ft} .7$ inch. in length lhs. one inch thick - - - - _ - _ - - 1210 400 feet surfuce of tubulated boiler at ten pounds per foot $-{ }^{-} \quad 4000$

Connecting parts, piston, \&c. say - $\quad-\quad-\quad-\quad$ - 2000

Water for an bour at 30 pounds per horse's power - $\quad 3000$

Coal for ditto at five pounds per ditto, being hore than sulfi- $\}$ 500
cient in Mr. Woolf's engines

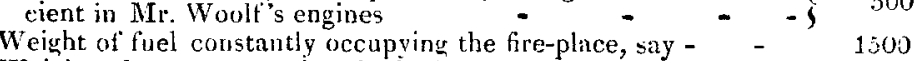

Weight of water occupying the builer - - $\quad-3000$

The pressure is estimated at 20 pounds per square inch, and the strolie 4 it. 8 inch. each second. 
weight of the steam-horse be deducted, there will remain 1750 pounds, which will, according to these estimates, be the weight of inert cargo in terms of horse powers which would be conveyed by this means. This is not a correct mode of estimating the matter in question; but I wish to show, by entering into this comparison of animal and engine power, how very much the latter exceeds the former in energy, weight for weight; and that even if the estimates should be so false as to be five-fold wrong, yet there would be sufficient power for the purpose. I shall deduct three times the weight of the engine estimated in the note from the 50 tons of power unoccupied in the balloon, when there will remain rather more than 34 tons of power for any purpose required. This would convey 500 men during one hour, 410 men during 12 hours, 290 men for 24 hours, and 50 men for 48 hours, without fresh supplies of fuel or water. The extent of the voyage in calm air would in the latter case be 960 miles.

I do not offer this statement with any expectation of its being realized in our age; but I do affirm that balloon navigation does hold out the capabilities I have so daringly ventured to investigate; and I trust that others will join Mr. Edgeworth and myself in promoting experiments upon a subject that promises eventually such advantage to mankind; the progress of civilization being evidently commensurate with the facility of communication. The expense of constructing the Montgolfier balloon described in my former paper, if taken at three shillings per yard including the inachinery, would be 870 pounds, and probably 1000 or 1500 pounds would defray the expenses of the experiment. The double cloth of the hydrogen gas balloon at six shillings would cost 3600 pounds, and , the engines, \&c. say from 6 to 7000 pounds; so that this inmense fabric, when compared to the large ships it seems to outvie, is not a tenth part of their cost. Their expense, however, when compared with their freight, will be about $300 \mathrm{l}$. per ton. The formation of hydrogen gas by the usual process is slow and expensive; but by keeping fresh supplies of iron borings red hot within an extensive ravity properly constructed, and passing steam through the hydrogen gas, may be supplied at a very cheap rate, and with considerable rapidity.

The vast strides which science of every kind has made within the last twenty years renders every advancing step more easy; and it appears to me that England may soon have the honour of perfecting the construction of balloons, although the invention of them was not altogether her own. The heavy expense, however, of such extensive experiments renders it necessary that it should become a national object; and as the means of directing balloons are within the scope of information of almost every 
every engineer in this mechanical country; the only real credit, that can be acquired in this pursuit, will be given to those when do actually realize the invention, and this will be due to each individual in proportion to the liberality with which he supports the undertaking.

Large individual subscriptions however are not necessary to obtain 1500l. and in fact subscriptions of one guinea are often more productive than those of a hundred. But whatever gentlemen may think proper to subscribe, whilst the subject is before them, I would request them to give notice of immediately, as by that means, and that alone, can any further step be taken before the subject will be forgotten.

I remain, sir,

$$
\text { Your obedient servant, }
$$

Brompton, April 5, 1816.

Geo. Caylex:

P.S.-The sketch represents an end view of a hydrogen gas balloon with three tiers of wing to be worked by the steanengine, or any other first mover; each wing to be divided into many stripes or portions, which are so constructed as to heel uj, and down by the alternate pressure of the air above and below them at each stroke of the engine, and thus by their oblique waft to propel the balloon.

LXV. Description of Mr. PhrLlips London's Hydrometer; with Remarks on the curing of Mackercl for Exportation or Winter Use*.

Sir, - I herhwirh send you a half barrel of mackerel, part of twenty-five thousand mackerel cured on my plan; also $\mathrm{Mr}$. Cutler's certificate, that so many were cured at Ramsgate during the last season, most of which were shipped for Russia. They were all eured by immersion in brine of British solid salt, agreeably to the method I had the honour of communicating to the Society, and which is printed in the thirty-second volume of the Society's 'Transactions, p.204. The whole were extremely fine, and full as beautiful as the specimen sent, which I hope will meet the approbation of the Society.

$$
\text { I am, sir, }
$$

No. 57, Cannon-strcet, London,

$$
\text { Your obedient servant, }
$$
Feb. $14,1815$.

Phillips London.

To C. Taylor, M.D. Sec.

* From Transactions of the Society for the Encouragement of Arts, Munnifectures and Commerce, vol. xxxiii. for 1815.-The Suciety's silver niedial sct in gold was voted to Mr. London for this communication. 